\title{
BEBIDA LÁCTEA FERMENTADA FORMULADA COM Camellia sinensis
}

\author{
OTÁVIO AUGUSTO SILVA RIBEIRO* \\ CLEUBE ANDRADE BOARI** \\ CAMILA MARTINS FONSECA* \\ SILVANIA PEREIRA DE FIGUEIREDO* \\ DORA NEUMANN $* * *$ \\ LUIZ RONALDO ABREU****
}

\begin{abstract}
Caracterizou-se bebida láctea fermentada formulada com Camellia sinensis. Elaborou-se a infusão de folhas desidratas e picadas de C. sinensis em soro lácteo $(1 \% \mathrm{p} / \mathrm{v})$, a qual foi adicionada ao leite fermentado nas proporções de $10 \%, 20 \%, 30 \%$ e $40 \%$ (v/v). O controle consistiu em leite fermentado adoçado. As amostras foram submetidas às determinações de massa seca, umidade, resíduo mineral fixo, proteína, gordura, sódio, acidez titulável, atividade antioxidante total, contagem de bactérias láticas e viscosidade no tempo inicial de fabricação e após 15 e 30 dias de armazenamento. No tempo inicial de fabricação procedeu-se a determinação cromatográfica de compostos voláteis e a condução dos testes de aceitação e de intenção de compra das amostras. O teor de massa seca, a umidade, o resíduo mineral fixo e a contagem total de bactérias láticas não foram influenciados pela quantidade de infusão de C. sinensis adicionada. Houve redução nos teores de proteína, gordura e de sódio conforme se aumentou a percentagem de infusão. Verificou-se redução na viscosidade aparente e aumento na atividade antioxidante total do produto mediante elevação da quantidade de infusão adicionada. Observou-se melhor aceitação e maior intenção de compra para a formulação de bebida láctea fermentada com $30 \%$ de infusão de $C$. sinensis. A utilização de infusão de $C$. sinensis não descaracterizou o perfil de voláteis típico de bebidas lácteas fermentadas. Pressupõe-se que o linalol tenha sido o principal responsável por conferir o sabor e o aroma de $C$. sinensis ao produto.
\end{abstract}

PALAVRAS-CHAVE: Camellia sinensis; BACTÉRIAS LÁTICAS; COMPOSTOS VOLÁTEIS; ANÁLISE SENSORIAL.

* Mestrandos, Programa de Pós-Graduação em Zootecnia, Universidade Federal dos Vales do Jequitinhonha e Mucuri (UFVJM), Diamantina, MG (e-mail: guto-ribeiro@hotmail.com; kmilazootecnista@gmail.com; silfigueiredo.zoo@ hotmail.com).

** Doutor em Ciência dos Alimentos, Professor, Departamento de Zootecnia, UFVJM, Diamantina, MG (e-mail: c.boari@ ufvjm.edu.br).

*** Doutora em Alimentos e Nutrição, Professora, Departamento de Nutrição, UFVJM, Diamantina, MG (e-mail: neumann.d@ufvjm.edu.br).

**** Doutor em Ciência dos Alimentos, Professor, Departamento de Ciência dos Alimentos, Universidade Federal de Lavras, Lavras, MG (e-mail: Irabreu@dca.ufla.br). 


\section{INTRODUÇÃO}

O beneficiamento do soro, remanescente da fabricação de queijos, representa benefícios aos produtos dele obtidos, bem como à nutrição humana (CALDEIRA et al., 2010). Seu emprego para a produção de bebidas lácteas, por exemplo, pode contribuir à diversificação do perfil proteico do produto final com a incorporação de proteínas solúveis típicas do soro e, também, para elevar o teor de lactose, importante fonte de galactose, requerida à manutenção das atividades cerebrais normais (BOGGS et al., 2010; STELWAGEN, 2011; LAMB et al., 2013). O processamento do soro contribui para a geração de receita às organizações do setor de lácteos e para a redução de seu impacto ambiental, pois o soro apresenta alto poder poluente e requer tratamento de elevado custo.

O processamento de bebidas lácteas fermentadas admite a utilização de aditivos alimentares não lácteos, o que faz desse alimento potencial veículo para diversos tipos de matérias-primas, oriundas das mais distintas origens. Permite-se ao setor produtivo, portanto, o desenvolvimento de produtos adicionados com ingredientes cujas pesquisas demonstrem benefícios ao metabolismo humano decorrentes de seu consumo regular, como a Camellia sinensis (L.) Kuntze, erva com a qual se prepara o chá verde.

Há tendência de aumento no consumo de $C$. sinensis em razão das elucidações científicas e da ampla divulgação de seus efeitos benéficos à saúde humana, dentre os quais a atividade antioxidante, o auxílio na redução de gordura corporal devido a processos de oxidação lipídica e diminuição da absorção de colesterol. Tais efeitos desejáveis são promovidos pela presença de polifenois, ácido ascórbico, alfa-tocoferol e carotenoides (MCKAY e BLUMBERG, 2002; LIMA et al., 2009).

Esta pesquisa foi conduzida com o objetivo de caracterizar bebida láctea fermentada formulada com C. sinensis.

\section{MATERIAL E MÉTODOS}

\subsection{OBTENÇÃO DO SORO LÁCTEO DOCE}

O soro doce foi obtido pela coagulação enzimática de leite pasteurizado a $65{ }^{\circ} \mathrm{C}$ por 30 minutos, resfriado a $37^{\circ} \mathrm{C}$ e adicionado de renina com poder coagulante 1:10.000 (Chr-Hansen ${ }^{\circledR}$, Valinhos, São Paulo, Brasil). Após a coagulação, procedeu-se o corte da massa, o descanso, mexedura e a enformagem da massa para concluir a produção de queijo tipo Minas frescal (SABOYA et al., 1998). Durante esse processo, o soro foi drenado do tanque, filtrado com dessorador e armazenado a $4{ }^{\circ} \mathrm{C}$ até o momento de seu uso.

\subsection{PRODUÇÃO DA INFUSÃO DE C. Sinensis EM SORO DOCE}

Produziu-se a infusão de $C$. sinensis utilizando o próprio soro, previamente obtido. Aqueceu-se o soro a $85{ }^{\circ} \mathrm{C}$, momento em que foram adicionadas e homogeneizadas as folhas de $C$. sinensis desidratadas e picadas, na proporção de $1 \%(\mathrm{p} / \mathrm{v})$, mantendo-se a mistura nessa temperatura por 10 minutos. Posteriormente, a infusão foi coada em coador de náilon para remoção dos resíduos vegetais e resfriada a $4{ }^{\circ} \mathrm{C}$, sendo assim mantida até o momento de sua utilização.

As folhas $C$. sinensis foram produzidas no município de Registro, Vale do Ribeira, São Paulo (latitude: 24 29' 13" S; longitude: 470 50'17" O) no ano de 2012.

\subsection{PRODUÇÃO DA BEBIDA LÁCTEA FERMENTADA}

Para a produção da bebida láctea fermentada homogeneizou-se o leite bovino cru com açúcar cristal (10\% p/v). A mistura foi filtrada em coador de náilon para remoção de sujidades, possivelmente 
presentes no açúcar, e pasteurizada a $65^{\circ} \mathrm{C}$ por 30 minutos em fermenteira confeccionada em aço inoxidável AISI \# 304, com camisa dupla, abastecida com vapor para aquecimento e água fria para o resfriamento.

Após a pasteurização, o leite foi resfriado a $42{ }^{\circ} \mathrm{C}$, momento em que adicionou-se cultivo lático termofílico liofilizado contendo Streptococcus salivarius subsp. thermophilus e Lactobacillus delbrueckii subsp. bulgaricus (Chr-Hansen ${ }^{\circledast}$, Valinhos, São Paulo, Brasil) na proporção de $1,5 \%(\mathrm{p} / \mathrm{v})$. A mistura foi incubada a $42{ }^{\circ} \mathrm{C}$, com monitoramento da acidez titulável até que fossem atingidos, aproximadamente, $80^{\circ}$ Dornic.

A infusão de $C$. sinensis, realizada em próprio soro, foi adicionada ao leite fermentado durante a quebra do gel, por agitação manual, nas proporções de $10 \%, 20 \%, 30 \%$ e $40 \%$ (v/p). Optou-se pela adição da infusão em soro $\left(4^{\circ} \mathrm{C}\right)$ nesse momento para preservar os compostos benéficos naturais da $C$. sinensis que poderiam ser danificados durante a pasteurização e fermentação do leite. Concomitantemente à homogeneização, as formulações foram rapidamente resfriadas a $12{ }^{\circ} \mathrm{C}$ para reduzir a atividade fermentativa das bactérias termofílicas.

As formulações foram embaladas em recipientes de polietileno e armazenadas a $12{ }^{\circ} \mathrm{C}$ por 18 horas para maturação. Finalizado o período de maturação, o produto foi resfriado a $4{ }^{\circ} \mathrm{C}$ e assim mantido até o momento das análises de interesse (tempo inicial, 15 e 30 dias).

O tratamento controle consistiu em formulação padrão de iogurte, adoçado com sacarose $10 \%(p / p)$

\subsection{ANÁLISES FÍSICO-QUÍMICAS E ATIVIDADE ANTIOXIDANTE TOTAL}

A acidez titulável ('Dornic) foi determinada pela titulação de alíquotas de 10 gramas das formulações de bebidas lácteas homogeneizadas em $10 \mathrm{~mL}$ de água destilada, com solução $\mathrm{NaOH}$ 0,1M (INSTITUTO ADOLFO LUTZ, 2008). Determinou-se a massa seca $\left(\mathrm{g} .100 \mathrm{~g}^{-1}\right)$ das amostras por diferença de umidade, previamente obtida em estufa a $105^{\circ} \mathrm{C}$ (AOAC, 2005; INSTITUTO ADOLFO LUTZ, 2008). O teor de gordura $\left(\mathrm{g} .100 \mathrm{~g} \mathrm{~g}^{-1}\right)$ foi determinado pelo método de Gerber (INSTITUTO ADOLFO LUTZ, 2008) e o de proteína $\left(100 \mathrm{~g}^{-1}\right)$ pelo método de semi-micro Kjeldahl, compreendendo as etapas de digestão, destilação e titulação das amostras com solução padrão de ácido clorídrico 0,1 mol.L-1 (AOAC, 2005; INSTITUTO ADOLFO LUTZ, 2008). O resíduo mineral fixo foi determinado por incineração de alíquotas das amostras em forno tipo mufla a $550^{\circ} \mathrm{C}$ até peso constante (AOAC, 2005; INSTITUTO ADOLFO LUTZ, 2008).

$\mathrm{Na}$ infusão de $C$. sinensis em soro lácteo doce foram determinados o teor de massa seca (g.100 g ${ }^{-1}$ ), o pH e a acidez titulável ('Dornic) (AOAC, 2005; INSTITUTO ADOLFO LUTZ, 2008).

Realizou-se a quantificação de sódio do produto a partir de cinzas úmidas, empregando-se fotômetro de chama (B 462, Tecnal) (CECCHI, 2003; INSTITUTO ADOLFO LUTZ, 2008), calibrado com soluções padrão de sódio em concentrações de 40, 80 e 100 ppm. Calculou-se o teor de sódio pela fórmula: $\mathrm{Na}=[(\mathrm{L}-\mathrm{b}) \div \mathrm{a}] \times(\mathrm{Pf} \div \mathrm{Pi})$, sendo: $\mathrm{L}=$ leitura realizada pelo aparelho; $b=$ constante 2,932; $\mathrm{a}=$ constante 1,028; $\mathrm{Pf}=$ peso da amostra analisada no fotômetro; $\mathrm{Pi}=$ peso da amostra utilizada para a extração da cinza úmida.

Determinou-se a atividade antioxidante total das formulações em função da reação de redução do radical livre 1,1-difenil-2-(2,4,6-trinitrofenil) hidrazila (DPPH), conforme método adaptado de Larrauri, Rupérez e Saura-Calixto (1997) e Rufino et al. (2007).

Obteve-se o extrato adicionando $40 \mathrm{~mL}$ de metanol $50 \%$ (v/v) em $25 \mathrm{~g}$ das amostras. Essa mistura foi homogeneizada e mantida em repouso por 60 minutos em temperatura ambiente. Centrifugou-se a mistura a $15.000 \mathrm{rpm}$, por 15 minutos, sendo o sobrenadante transferido para balão volumétrico com capacidade de $100 \mathrm{~mL}$. O resíduo da primeira extração foi adicionado de $40 \mathrm{~mL}$ de acetona $70 \%(\mathrm{v} / \mathrm{v})$, sendo homogeneizado e mantido em repouso por 60 minutos em temperatura ambiente. Realizou-se outra centrifugação a $15.000 \mathrm{rpm}$, durante 15 minutos, sendo o sobrenadante transferido para o balão volumétrico contendo o primeiro sobrenadante. Completou- 
se o volume de $100 \mathrm{~mL}$ com água destilada. A solução de DPPH foi preparada dissolvendo-se 2,4 mg de DPPH em $100 \mathrm{~mL}$ de metanol.

Para a determinação da atividade antioxidante total, alíquotas de $0,1 \mathrm{~mL}$ do extrato previamente obtido foram transferidas em ambiente escuro para tubos contendo $3,9 \mathrm{~mL}$ do radical DPPH 0,06 mM. O branco consistiu na homogeneização de $0,1 \mathrm{~mL}$ de solução controle (álcool metílico, acetona e água) com $3,9 \mathrm{~mL}$ do radical DPPH. Utilizou-se álcool metílico, como branco, para calibração do espectrofotômetro UV-Vis (Hitachi U2010). As leituras (515 nm) foram monitoradas a cada minuto, observando-se a redução da absorbância até sua estabilização. Após as leituras, calculou-se a atividade antioxidante total pela fórmula: $A A T=(A b C-A b L) \div A b c$, sendo: $A b C=$ absorbância do controle; $A b L=$ absorbância da amostra. Os resultados foram expressos em percentual de inibição da atividade da enzima DPPH (ATT \%).

\subsection{QUANTIFICAÇÃO DE BACTÉRIAS LÁTICAS}

Procedeu-se à quantificação de bactérias láticas totais pelo plaqueamento de alíquotas de $1 \mathrm{~mL}$ das diluições em profundidade, utilizando-se ágar MRS (Himedia Laboratories, Mumbai, Índia), com adição de sobrecamada. A incubação foi realizada em estufa BOD, à temperatura de $42^{\circ} \mathrm{C}$ por 48 horas, sendo os resultados expressos em log UFC. g $^{-1}$ (APHA, 2001).

\subsection{VISCOSIDADE APARENTE}

Determinou-se a viscosidade aparente das amostras, mantidas a $10^{\circ} \mathrm{C}$, em viscosímetro digital programável (Brookfield DVIII), utilizando sonda cilíndrica $\mathrm{n}^{\circ} 4$ e velocidade de $50 \mathrm{rpm}$, durante 20 minutos (CUNHA NETO et al., 2005). O equipamento foi programado para realizar 17 medições, com intervalo de tempo de 35,3 segundos para cada ponto de medição. Os resultados foram expressos em Centipoise (cP).

\subsection{ANÁLISE SENSORIAL}

Testes de aceitação e de intenção de compra das bebidas foram realizados com 60 julgadores não treinados, verbalmente recrutados, os quais receberam informação prévia sobre o produto. Amostras com $50 \mathrm{~g}$ das formulações, em temperatura de aproximadamente $4{ }^{\circ} \mathrm{C}$, foram servidas aos julgadores em cabines, de forma aleatória, em copos plásticos descartáveis, codificados com números de três dígitos. Os julgadores preencheram fichas para informar preferência, aceitação (cor, sabor, textura e impressão global em escala hedônica de 9 pontos ancorada nos extremos por 'desgostei muitíssimo' e 'gostei muitíssimo') e intenção de compra (escala de 5 pontos ancorada nos extremos por 'compraria sempre' a 'nunca compraria) (INSTITUTO ADOLFO LUTZ, 2008).

\subsection{ANÁLISE CROMATOGRÁFICA DE COMPOSTOS VOLÁTEIS}

Procedeu-se à determinação de compostos voláteis empregando cromatógrafo a gás (Hewlet-Packard, modelo 5890), acoplado a espectrômetro de massa (HP-MSD-5970). A separação ocorreu em coluna de sílica fundida LM 5, com $30 \mathrm{~m}$ e 0,25 mm de diâmetro interno. As condições cromatográficas foram: gás de arraste He ultra puro, com velocidade linear de $32 \mathrm{~cm} / \mathrm{seg}$; temperatura injetor, $250^{\circ} \mathrm{C}$; temperatura detector, $280^{\circ} \mathrm{C}$; fonte de impacto de elétrons, $70 \mathrm{eV}$; injetor, split com razão de divisão de 1:20; e volume injetado de $3 \mu \mathrm{L}$. Utilizou-se analisador quadrupolo e integrador HP 9133, sendo os compostos voláteis identificados por espectrometria de massas e índice de Kovats (PHEROBASE, 2012).

\subsection{DELINEAMENTO EXPERIMENTAL E ANÁLISES ESTATÍSTICAS}

Conduziu-se esta pesquisa em delineamento inteiramente casualizado, arranjado em 
esquema fatorial $5 \times 3$ (formulação; tempo), com quatro repetições. Os dados das análises físicoquímicas, da quantificação de bactérias láticas, da viscosidade aparente e da atividade antioxidante total foram submetidos a análises de variância e regressão, utilizando-se o programa Statistical Analysis System (SAS, 2002), versão 9.0.

A análise sensorial foi conduzida em blocos balanceados, sendo os dados gerados pelo teste de aceitação submetidos à análise de variância e teste de Tukey, com probabilidade de $5 \%$, utilizando-se o programa Statistical Analysis System, versão 9.0. (SAS, 2002). Os dados pertinentes ao teste de intenção de compra foram expressos em percentual.

\subsection{ANÁLISE DO COMITÊ DE ÉTICA EM PESQUISA}

O ensaio experimental envolvendo seres humanos foi aprovado pelo Comitê de Ética em Pesquisa (CAAE 16251413.4.0000.5108).

\section{RESULTADOS E DISCUSSÃO}

\subsection{CARACTERÍSTICAS FÍSICO-QUÍMICAS E ATIVIDADE ANTIOXIDANTE TOTAL}

A infusão de $C$. sinensis em soro lácteo doce apresentou teor de massa seca de $7,54 \mathrm{~g}$. $100 \mathrm{~g}^{-1},( \pm 0,36), \mathrm{pH}$ de $6,48( \pm 0,19)$ e acidez titulável de $14,14{ }^{\circ}$ Dornic $( \pm 1,65)$. $O$ teor de massa seca mostrou-se semelhante ao relatado por Teixeira e Fonseca (2008) avaliando soro de queijo. O valor de $\mathrm{pH}$ e a acidez titulável enquadraram-se na faixa de valores normalmente observáveis no leite cru (BRASIL, 2011).

Na Tabela 1 são apresentadas as características físico-químicas e a atividade antioxidante total de formulações de bebida láctea fermentada, adicionada com diferentes proporções de infusão de $C$. sinensis, em três períodos de armazenamento (tempo inicial, 15 e 30 dias), mantida em refrigeração $\left(4^{\circ} \mathrm{C}\right)$.

Os teores de massa seca, de umidade e de resíduo mineral fixo não foram alterados $(P \geq 0,05)$ pela quantidade de infusão adicionada ou pelo tempo de armazenamento. Entretanto, quanto maior a quantidade de infusão adicionada menores $(P<0,05)$ foram os quantitativos de proteína, de gordura e de sódio, o que pode ser entendido como consequência de sua diluição no produto, devido ao baixo teor desses constituintes no soro lácteo (TEIXEIRA e FONSECA, 2008).

Penna e Thammer (2005) descreveram reduções nos teores de gordura e de protídeos de bebidas lácteas como consequência da adição de maiores proporções de soro lácteo. Thamer e Penna (2006) afirmaram que embora o soro apresente menor teor proteico, sua importância nutricional é indiscutível. Trata-se de fonte de $\beta$-lactoglobulina, a-lactoalbumina, soroalbumina, imunoglobulinas, proteose-peptonas, lactoferrina, transferrina, vitaminas hidrossolúveis (tiamina, riboflavina, ácido pantotênico, vitamina B6 e B12), minerais (cálcio, magnésio, zinco e fósforo) e lactose. Caldeira et al. (2010) relataram redução significativa dos quantitativos de proteínas e lipídios conforme aumentaram a proporção de soro adicionado em formulações de bebida láctea com leite bubalino, mas não observaram alterações significativas nos teores de massa seca, de umidade e de resíduo mineral fixo. Mesmo havendo redução no teor de protídeos, as formulações atenderam ao requisito oficial para este parâmetro que prevê teor mínimo de $1,7 \mathrm{~g} .100 \mathrm{~g}^{-1}$ de proteína láctea (BRASIL, 2005). Para elevar e padronizar o teor proteico da bebida láctea deve-se avaliar o prévio enriquecimento do leite a ser beneficiado com sólidos lácteos.

Considerando as recomendações da Organização Mundial da Saúde (WHO, 2012) de consumo diário de $2.000 \mathrm{mg}$ de sódio, as formulações apresentaram baixo teor desse elemento. Como forma de ilustração, considerando-se o valor médio de sódio de $5,5 \mathrm{mg} .100 \mathrm{~g} \mathrm{~g}^{-1}$ seria necessário o consumo diário de 36 quilos da bebida láctea fermentada com $C$. sinensis para que 
fosse atingido o limite máximo recomendado. Admite-se, portanto, que esse produto atenderia as demandas de segmentos de mercado por alimentos hipossódicos. Os quantitativos de sódio das formulações foram inferiores ao valor médio de $34,7 \mathrm{mg} .100 \mathrm{~g}^{-1}$ observado em leite bovino cru por Sola-Larranaga e Navarro-Blasco (2009).

\section{TABELA 1 - CARACTERÍSTICAS FÍSICO-QUÍMICAS E ATIVIDADE ANTIOXIDANTE TOTAL DE BEBIDA LÁCTEA FERMENTADA FORMULADA COM Camellia sinensis EM TRÊS PERÍODOS DE ARMAZENAMENTO (TEMPO INICIAL, 15 E 30 DIAS), REFRIGERADA A $4{ }^{\circ} \mathrm{C}$}

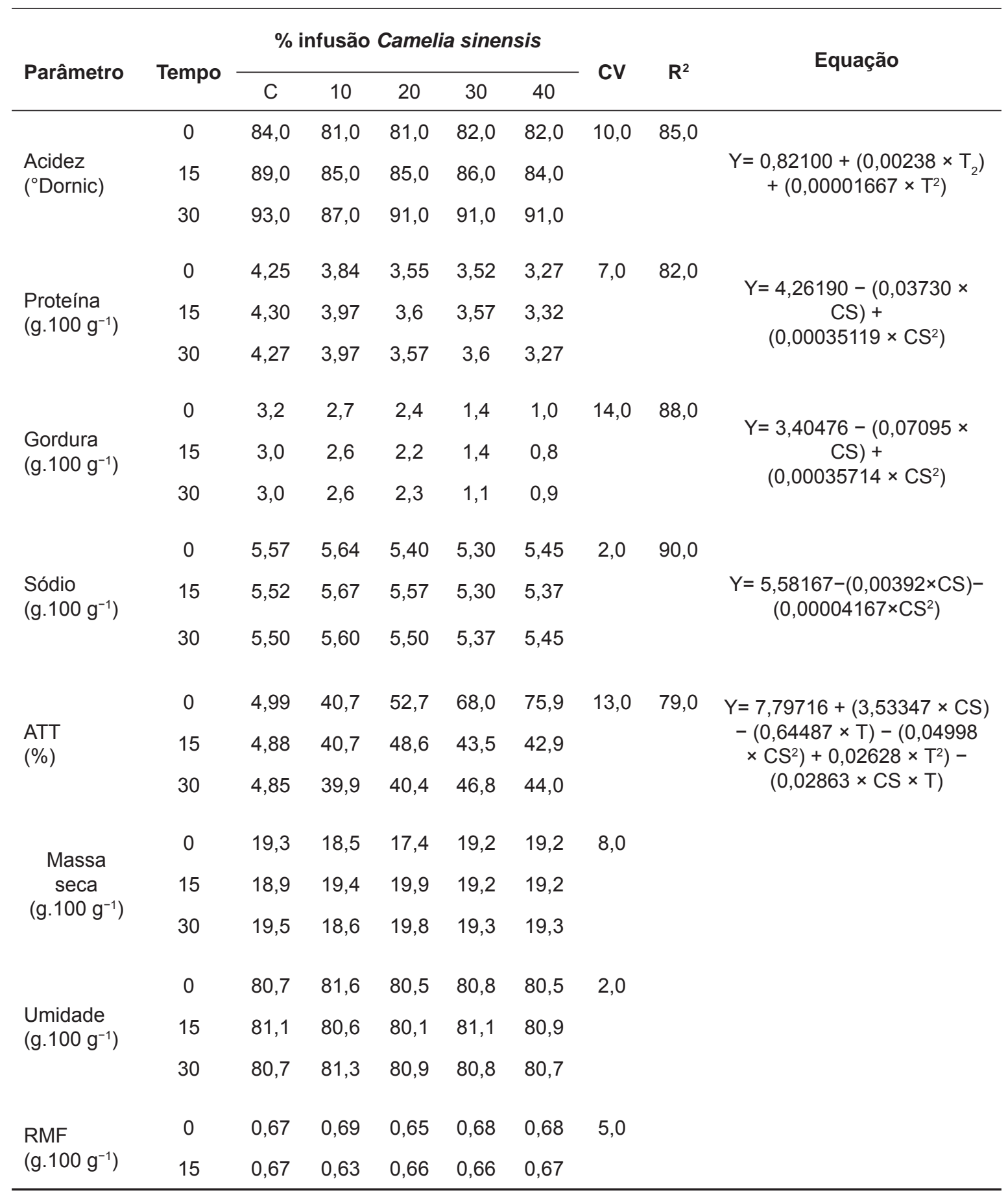

ATT = atividade antioxidante total; RMF = resíduo mineral fixo; C = Controle; CV = coeficiente de variação; $\mathrm{R}^{2}=$ coeficiente de determinação. 
Embora a infusão de $C$. sinensis tenha apresentado valor de acidez titulável $(14,14 \pm$ $1,65^{\circ}$ Dornic) inferior à do leite após fermentação, a quantidade adicionada não influenciou $(P \geq$ $0,05)$ a acidez final das formulações. No entanto, houve aumento $(P<0,05)$ na acidez titulável das bebidas lácteas durante o período de armazenamento, fato descrito na literatura como pósacidificação (ROCHA et al., 2008; VAHEDI, TEHRANI e SHAHIDI, 2008). Kauser et al. (2011) relataram que em produtos lácteos fermentados, mesmo quando estocados em condições de temperaturas bacteriostáticas para micro-organimos termófilos, pode ocorrer atividade microbiana fermentativa suficiente para alterar a acidez do produto ao longo de sua vida útil.

A atividade antioxidante total, avaliada como o percentual de inibição da atividade da enzima DPPH, foi significativamente mais elevada $(P<0,05)$ quanto maior a quantidade de infusão adicionada. Esse fato pode ser entendido pela maior inserção de moléculas captadoras de radicais livres de ocorrência natural da $C$. sinensis, principalmente, catequina, epicatequina, epigalocatequina galato, cafeína e ácido ascórbico (POLOVKA et al., 2003; KODAMA et al., 2010; JUN et al., 2011; ZHANG et al., 2013). Nishiyama et al. (2010) observaram percentual de inibição da DPPH entre $70 \%$ a $75 \%$ em chá verde recém-preparado, dado semelhante ao observado nas formulações contendo $30 \%$ e $40 \%$ de infusão no tempo inicial de fabricação.

A atividade antioxidante das formulações com $10 \%, 20 \%, 30 \%$ e $40 \%$ de C. sinensis foi em média $8,11,14$ e 15 vezes superior, respectivamente, àquela observada na formulação controle.

Confrontando-se os resultados obtidos com dados publicados na literatura, a atividade antioxidante da bebida láctea foi superior àquela relatada por Kodama et al. (2010), que verificaram atividade antioxidante de $44 \%$ em amostras comerciais de chá verde. Chan et al. (2007) constataram atividade antioxidante de $85 \%$ em brotos de $C$. sinensis e o máximo de $44 \%$ em plantas adultas.

Verificou-se redução $(\mathrm{P}<0,05)$ da atividade antioxidante das formulações de bebida láctea com C. sinensis ao longo do período de armazenamento. Esse evento pode ser justificado pela degradação de moléculas e perda de sua bioatividade, bem como pela própria reação entre os componentes antioxidantes e radicais livres porventura formados no produto ao longo do período de armazenamento como, oxigênio, hidroperóxidos, radicais alquila e peroxila.

Dentre os mecanismos de consumo de antioxidantes, Castelo-Branco e Torres (2011) mencionaram a auto-oxidação de lipídeos, que pode iniciar espontaneamente e ser acelerada por pró-oxidantes, como os metais de transição, pela exposição à luz visível, em presença de fotossensibilizador, por elevadas temperaturas e pela presença de oxigênio.

\subsection{BACTÉRIAS LÁTICAS}

$\mathrm{Na}$ Tabela 2 são apresentadas as contagens de bactérias láticas em bebida láctea fermentada adicionada com diferentes proporções de infusão de $C$. sinensis, em três períodos de armazenamento (tempo inicial, 15 e 30 dias) refrigerado $\left(4^{\circ} \mathrm{C}\right)$.

\section{TABELA 2 - CONTAGENS DE BACTÉRIAS LÁTICAS EM BEBIDA LÁCTEA FERMENTADA FORMULADA COM Camellia sinensis EM TRÊS PERÍODOS DE ARMAZENAMENTO (TEMPO INICIAL, 15 E 30 DIAS)}

\begin{tabular}{lcllllll}
\hline \multirow{2}{*}{ Parâmetro } & Tempo & \multicolumn{5}{c}{ \% infusão Camelia sinensis } \\
\cline { 3 - 7 } & (dias) & $\mathrm{C}$ & 10 & 20 & 30 & 40 & CV \\
\hline \multirow{2}{*}{ CBL } & 0 & 7,3 & 7,4 & 7,91 & 7,8 & 7,74 & 15,3 \\
(logUFC. (-1) $\left.^{-1}\right)$ & 15 & 7,47 & 7,3 & 7,85 & 7,9 & 7,62 & \\
& 30 & 7,85 & 7,69 & 7,9 & 7,6 & 7,6 & \\
\hline
\end{tabular}

$\mathrm{CBL}=$ contagem total de bactérias láticas; UFC = unidades formadoras de colônia; CV = coeficiente de variação. 
A contagem total de bactérias láticas não se alterou de forma significativa $(P \geq 0,05)$ em função da quantidade de infusão adicionada, ou do período de armazenamento pesquisado.

Um dos principais parâmetros de qualidade de bebidas lácteas fermentadas consiste na sobrevivência e na viabilidade de bactérias láticas durante a vida útil do produto. Por esta razão, ao pesquisar novos aditivos e ingredientes deve-se avaliar sua ação perante estes micro-organismos benéficos. Foi constatado que as proporções de infusão de $C$. sinensis avaliadas não exerceram efeito deletério sobre a viabilidade dessas bactérias. Todas as formulações atenderam ao padrão oficial para bebidas lácteas (BRASIL, 2005), o qual estabelece contagem mínima de 6 Log UFC.g ${ }^{-1}$ para tais micro-organismos.

\subsection{VISCOSIDADE APARENTE}

Na Tabela 3 é apresentada a viscosidade aparente de formulações de bebida láctea fermentada adicionada com diferentes proporções de infusão de $C$. sinensis, em três períodos de armazenamento (tempo inicial, 15 e 30 dias), mantidas em refrigeração $\left(4^{\circ} \mathrm{C}\right)$.

\section{TABELA 3 - VISCOSIDADE APARENTE DE BEBIDA LÁCTEA FERMENTADA FORMULADA COM Camellia sinensis EM TRÊS PERÍODOS DE ARMAZENAMENTO (TEMPO INICIAL, 15 E 30 DIAS)}

\begin{tabular}{|c|c|c|c|c|c|c|c|c|c|}
\hline \multirow{2}{*}{ Parâmetro } & \multirow{2}{*}{ Tempo } & \multicolumn{5}{|c|}{ \% infusão Camelia sinensis } & \multirow[b]{2}{*}{ CV } & \multirow[b]{2}{*}{$\mathbf{R}^{2}$} & \multirow{2}{*}{ Equação } \\
\hline & & C & 10 & 20 & 30 & 40 & & & \\
\hline \multirow{3}{*}{$\begin{array}{l}\text { Viscosidade } \\
\text { aparente } \\
\text { (cP) }\end{array}$} & 0 & 2786 & 1069 & 1057 & 1003 & 980 & & & \multirow{3}{*}{$\begin{array}{c}Y=2587,13324- \\
(129,13393 \times C S)+ \\
(2,29227 \times C S)\end{array}$} \\
\hline & 15 & 2735 & 1063 & 1051 & 1012 & 986 & 18 & 87 & \\
\hline & 30 & 2753 & 1055 & 1049 & 946 & 920 & & & \\
\hline
\end{tabular}

$\mathrm{CP}=$ centipoise $\mathrm{C}=$ controle $; \mathrm{CV}=$ coeficiente de variação. $\mathrm{R}^{2}=$ coeficiente de determinação.

A viscosidade das formulações foi significativamente $(P<0,05)$ menor quanto maior as proporções de infusão adicionadas.

De acordo Seckin e Ozkilinc (2011) e Grygorczyk et al. (2013), a textura de lácteos fermentados é relevante tanto para sua caracterização quanto para sua aceitação pelo consumidor. Nesse contexto, Sandoval-Castilla et al. (2004) relataram que ao se desenvolver novo produto é de fundamental importância avaliar o efeito de processos e novos ingredientes sobre esses parâmetros.

A viscoelasticidade e plasticidade do gel de bebidas lácteas são sensivelmente afetadas por fatores como o tratamento térmico do leite, o qual promove a desnaturação de proteínas e, consequentemente, eleva sua capacidade de retenção de água (SANDOVAL-CASTILLA et al., 2004; DAMIN et al., 2009). Além disso, a quantidade e o perfil hidrofílico/hidrofóbico dos ingredientes adicionados, os teores de proteína e de gordura e a acidez são determinantes para alterar a textura do produto (HEKMAT e REID, 2006; CODA et al., 2012). Como consequência da desestabilização do gel são ocasionados defeitos no produto, como a sinérese excessiva, formação de fase, surgimento de grânulos e redução na viscosidade.

Quanto maior a proporção de infusão adicionada menores foram os teores de gordura e de proteína e, por fim, menor a viscosidade do produto. Por essa razão, a formulação com $40 \%$ de infusão, que apresentou menores teores desses constituintes, também evidenciou a menor viscosidade. 


\subsection{ACEITAÇÃO E INTENÇÃO DE COMPRA}

A aceitação e a intenção de compra das formulações de bebida láctea fermentada elaborada com C. sinensis são apresentadas na Tabela 4.

\section{TABELA 4 - ACEITAÇÃO PARA APARÊNCIA, SABOR, TEXTURA E IMPRESSÃO GLOBAL E INTENÇÃO DE COMPRA DE BEBIDA LÁCTEA FERMENTADA FORMULADA COM Camellia sinensis}

\begin{tabular}{|c|c|c|c|c|c|c|c|c|c|}
\hline \multirow{2}{*}{$\% \mathrm{CS}$} & \multicolumn{4}{|c|}{ Aceitação (escore: 0-10) } & \multicolumn{5}{|c|}{ Intenção de compra (\%) } \\
\hline & $A$ & $S$ & $\mathrm{~T}$ & IG & $\mathrm{Se}$ & $\mathrm{Fr}$ & Oc & $\mathrm{R}$ & NC \\
\hline 10 & $7,2 \mathrm{a}$ & $7,1 \mathrm{a}$ & $7,2 \mathrm{a}$ & $7,2 \mathrm{a}$ & 36,7 & 35,0 & 20,0 & 5,0 & 3,3 \\
\hline 20 & $7,0 \mathrm{a}$ & $6,9 a$ & $7,0 \mathrm{a}$ & $7,1 \mathrm{a}$ & 38,3 & 40,0 & 16,7 & 4,0 & 1,0 \\
\hline 30 & $7,0 \mathrm{a}$ & $7,1 \mathrm{a}$ & $6,8 \mathrm{a}$ & $7,0 \mathrm{a}$ & 41,7 & 46,7 & 8,3 & 1,7 & 1,7 \\
\hline 40 & $6,7 \mathrm{a}$ & $6,4 \mathrm{a}$ & $6,2 \mathrm{a}$ & $6,4 \mathrm{~b}$ & 31,7 & 36,7 & 25,0 & 5,0 & 1,7 \\
\hline
\end{tabular}

\% CS = percentagem de C. sinensis; $\mathrm{A}=$ aparência; $\mathrm{S}=$ sabor; $\mathrm{T}$ = textura; IG = impressão global; Se = compraria sempre; $\mathrm{Fr}$ = compraria frequentemente; $\mathrm{Oc}=$ compraria ocasionalmente; $\mathrm{R}=$ compraria raramente; $\mathrm{NC}=$ nunca compraria. Médias em coluna seguidas pela mesma letra não diferem entre si, de acordo com o teste de Tukey, em probabilidade de $5 \%$.

A proporção de infusão de $C$. sinensis adicionada não influenciou $(P \geq>0,05)$ a aceitação do produto, no que se refere à sua aparência.

Com relação ao sabor, as formulações com $10 \%, 20 \%$ e $30 \%$ de infusão foram as mais aceitas. Conforme manifestado por escrito pelos julgadores nas fichas de avaliação, a formulação com $40 \%$ apresentou sabor forte e amargo, sendo relatada também sua adstringência.

Conforme Siebert, Maekawa e Lynn (2011) infusões com C. sinensis podem apresentar elevado teor de polifenois (catequinas), os quais têm sido associados ao seu amargor e adstringência. Nesse contexto, Rossetti et al. (2009) e Nayak e Carpenter (2008) descreveram a adstringência oral como fenômeno comumente associado a chás, decorrente da presença dos polifenois, o qual resulta da precipitação de proteínas presentes na saliva, responsáveis pela lubrificação da cavidade oral. Por essa razão, eleva-se o coeficiente de atrito entre os tecidos da boca, promovendo a sensação descrita por boca seca.

Para a textura, as formulações contendo $10 \%, 20 \%$ e $30 \%$ de infusão apresentaram maior aceitação e a bebida láctea com $40 \%$ a menor. Alguns avaliadores mencionaram que a bebida com 40 \% de infusão 'estava rala' e assim justificaram a menor aceitação por sua textura. Conforme Caldeira et al. (2010) adições de soro, em menores proporções, permitem a obtenção de produtos com consistência mais semelhante ao iogurte, fato que contribui para sua maior aceitação. Ainda conforme estes autores, a adição de maiores quantidades de soro pode produzir efeitos indesejados nas bebidas lácteas, como a separação de fases. Nesta pesquisa realizou-se análise sensorial no produto recém-fabricado, não sendo observada separação de fases durante seu manuseio, fato que justifica a ausência de efeito significativo $(P \geq 0,05)$ sobre a aparência.

Com relação à impressão global, os julgadores demostraram maior aceitação para as formulações contendo $10 \%, 20 \%$ e $30 \%$ de infusão de C. sinensis. Presume-se, pelo contexto anteriormente exposto, que os atributos sabor e textura influenciaram sensivelmente a aceitação global desse produto.

Independente do percentual de infusão adicionado, a maior proporção de avaliadores manifestou interesse em sempre comprar o produto ou em comprá-lo frequentemente.

Embora não tenha havido diferença significativa $(P \geq 0,05)$ na aceitação do sabor, alguns avaliadores informaram, por escrito nas fichas, que as bebidas com $10 \%$ e $20 \%$ apresentaram sabor muito sútil e que a formulação com $30 \%$ mostrou sabor mais intenso. Todas as formulações 
recém-fabricadas, incluindo a com $40 \%$ de infusão adicionada, apresentaram baixa rejeição (menos de $4 \%$ dos indivíduos assinalaram a opção de nunca comprar o produto).

\subsection{COMPOSTOS VOLÁTEIS}

Na Tabela 5 são apresentados os compostos voláteis mais frequentes nas diferentes formulações de bebida láctea fermentada elaborada com infusão de C. sinensis (recém-fabricada), e na Tabela 6 os compostos voláteis menos frequentes.

TABELA 5 - COMPOSTOS VOLÁTEIS IDENTIFICADOS EM BEBIDA LÁCTEA FERMENTADA FORMULADA COM INFUSÃO DE Camellia sinensis, RECÉM-FABRICADA

\begin{tabular}{|c|c|c|c|c|c|c|}
\hline \multirow{2}{*}{ Composto } & \multirow[b]{2}{*}{ TR } & \multirow[b]{2}{*}{ IK } & \multicolumn{4}{|c|}{$\%$ área } \\
\hline & & & 10 & 20 & 30 & 40 \\
\hline 3-hidroxibutanona (ou acetoína) & 2,407 & 838 & 34,54 & 20,27 & 29,34 & 42,1 \\
\hline Propan-2-ona (ou acetona) & 1,25 & 812 & 12,86 & 26,43 & 34,1 & 14,22 \\
\hline 2,3-pentanodiona (ou acetil propionil) & 2,204 & 834 & 9,1 & 8,3 & 4,9 & 7,13 \\
\hline 2,3-butanodiona (ou diacetil) & 1,51 & 818 & 3,9 & 5,26 & 2,6 & 4,6 \\
\hline 2-heptanona & 5,796 & 918 & 4,21 & 3,8 & 2,47 & 2,72 \\
\hline Ácido butanoico (ou ácido butírico) & 3,433 & 862 & 2,64 & 1,15 & 2,73 & 2,81 \\
\hline Ácido hexanoico (ou ácido caproico) & 8,652 & 988 & 2,53 & 1,53 & 1,73 & 1,35 \\
\hline Hidroxietano & 1,185 & 811 & 1,95 & 2,13 & 2,56 & 2,94 \\
\hline Linalol & 12,577 & 1090 & 0,31 & 0,52 & 0,82 & 1,65 \\
\hline 2-metilpent-1-eno & 1,94 & 828 & 0,61 & 0,83 & 0,45 & 0,87 \\
\hline Etanal (ou acetaldeído) & 1,059 & 808 & 0,15 & 0,12 & 0,12 & 0,12 \\
\hline$(3 S, 4 S)-3,4-d i(m e t o x i m e t o x i)$ pirrolidina & 1,12 & 810 & 0,13 & 0,17 & 0,18 & 0,17 \\
\hline $\begin{array}{l}\text { 2,3,4,4-tetrapropil-1-(trimetisilil)-1- } \\
\text { (trimetilsililox)-1,3-diaza-2,4-diborabutano }\end{array}$ & 21,215 & 1334 & 0,19 & 0,23 & 0,12 & 0,10 \\
\hline Ácido acético & 9,224 & 0,13 & 1,35 & 0,17 & 1,55 & \\
\hline 1-metil-4-(1-metiletenil)ciclohexene & 10,191 & 1027 & 0,9 & & 0,87 & 1,58 \\
\hline Ácido benzenoacético & 14,934 & 1154 & 0,69 & & 0,61 & 0,53 \\
\hline 1-butanol 3-metil & 13,008 & 1101 & 0,31 & & 0,24 & 0,14 \\
\hline 3-fenilbutan-2-ol & 5,201 & 0,09 & 0,12 & 0,68 & & 0,09 \\
\hline
\end{tabular}

TR = tempo de retenção; IK = índice de Kovats; \% área = percentagem da área do gráfico. 
TABELA 6 - COMPOSTOS VOLÁTEIS IDENTIFICADOS EM BEBIDA LÁCTEA FERMENTADA FORMULADA COM INFUSÃO DE Camellia sinensis, RECÉM-FABRICADA

\begin{tabular}{|c|c|c|c|c|c|c|}
\hline \multirow{2}{*}{ Composto } & \multirow{2}{*}{ TR } & \multirow{2}{*}{ IK } & \multicolumn{4}{|c|}{ \% área } \\
\hline & & & 10 & 20 & 30 & 40 \\
\hline Butiraldeído & 1,596 & 819 & 2,16 & & & \\
\hline Ciclotrisiloxano hexametil & 4,102 & 877 & 0,45 & & & \\
\hline $\begin{array}{l}\text { Etanol 2-(2-ciclohexen-1-ilidene)-acetato-2- } \\
\text { (ciclohex-2-enilideno) etiletenoato }\end{array}$ & 4,806 & 899 & 0,30 & & & \\
\hline Hexahidro-3-hidroxi-1H-azepin-2-ona & 3,785 & 869 & 0,95 & 0,35 & & \\
\hline Etenilacetato & 1,528 & 822 & 4,26 & 6,06 & & \\
\hline 1-hexanol & 5,4 & 904 & 0,28 & 0,46 & & \\
\hline 3,4-dihidrothieno-(3,4-B)-5-carboxithiofeno & 1,636 & 821 & 3,33 & & 1,31 & \\
\hline 1-hidroxihexano & 2,175 & 828 & 0,64 & & 0,23 & \\
\hline 2-(metoximetil)oxirona & 3,936 & 872 & 0,66 & & 0,74 & \\
\hline (Diisopropilfosfino)-N,N-dimetilmetanamina & 1,318 & 814 & & 1,1 & & \\
\hline Butan-2-ona & 1,555 & 820 & & 2,8 & & \\
\hline Ácido propanoico & 2,105 & 832 & & 0,23 & & \\
\hline Éter metil-D3-1-dideutério-2-propenil & 2,309 & 839 & & 1,65 & & \\
\hline 1-butanol 2,3-epoxi-, trans- & 3,884 & 873 & & 0,46 & & \\
\hline 6,7-diazabiciclo[3,2,2,]nona-3,6-diene & 5,207 & 904 & & 0,55 & & \\
\hline Etil hexanoato & 9,259 & 1003 & & 1,37 & & \\
\hline Terpinil acetato & 10,198 & 1027 & & 0,7 & & \\
\hline Ácido benzoico & 4,067 & 877 & & 0,39 & 0,26 & \\
\hline Pentan-2-ona & 2,12 & 833 & & 0,24 & & 0,47 \\
\hline Metil laurato & 5,004 & 899 & & & 0,41 & \\
\hline 1,2-dimetil-benezeno & 5,199 & 904 & & & 0,98 & \\
\hline 1-propanol 3-metoxi & 1,56 & 819 & & & 1,3 & 4,6 \\
\hline 3-pentanol & 3,743 & 869 & & & 0,71 & 1,03 \\
\hline Propilciclopropano & 5,245 & 905 & & & 0,14 & 0,37 \\
\hline 3-pentanona 2,2,4,4-tetrametil & 2,101 & 832 & & & & 0,21 \\
\hline 1-nonaldeído & 3,677 & 868 & & & & 0,09 \\
\hline 1-metoxiacetona & 3,893 & 872 & & & & 0,74 \\
\hline Dodecahidro-6H-pirido[1,2-b]isoquinolin-6-ona & 4,062 & 877 & & & & 0,18 \\
\hline 1-propen-2-ol & 5,005 & 899 & & & & 0,17 \\
\hline Ácido 1H-pirrole-3-propanóico & 9,223 & 1003 & & & & 0,13 \\
\hline
\end{tabular}

TR = tempo de retenção; IK = índice de Kovats; \% área = percentagem da área do gráfico. 
A combinação de compostos voláteis, principalmente daqueles presentes em maior quantidade, contribui para a determinação do sabor e aroma característico dos alimentos (DE MARIA, MOREIRA e TRUGO, 1999; MOREIRA, TRUGO e DE MARIA, 2000). Os compostos voláteis associados ao sabor e ao aroma de bebidas lácteas podem estar naturalmente presentes no leite, serem formados durante sua fermentação e pela posterior atividade microbiana, bem como serem agregados ao produto por adição de ingredientes (como a infusão de $C$. sinensis).

Os compostos 3-hidroxibutan-2-eno (ou acetoína); propano-2-ona (ou acetona); 2,3-pentadiona (ou acetil propionil); 2,3-butanodiona (ou diacetil); 2-heptanona; ácido butanoico (ou ácido butírico); ácido hexanoico (ou ácido caproico); hidroxietano; e linalol estiveram majoritariamente presentes nas formulações de bebida láctea fermentada elaborada com $C$. sinensis e, por essa razão, talvez sejam os que mais se destacam na formação de seu sabor e aroma.

Resultados de pesquisas demonstram a ocorrência de alguns compostos identificados neste trabalho, tanto no leite quanto em diferentes tipos de lácteos, principalmente naqueles obtidos por fermentação (JANDAL, 1996; CHAMMAS et al., 2006; MACCIOLA, CANDELA e DE LEONARDIS, 2008; CODA et al., 2012). Licón et al. (2012) relataram a associação do sabor e do aroma de queijo produzido com leite de ovelha à ocorrência de 2,3-pentanodiona; propanol; 2-butanona; nonanal; acetona; e benzeno. Servili et al. (2011) destacaram 2-pentanona e 2-heptanona como importantes compostos do aroma de bebidas lácteas fermentadas, sendo a sua formação atribuída a $\beta$-oxidação de ácidos graxos saturados livres e descarboxilação de ácidos ceto-beta. Magalhães et al. (2011) mencionaram a ocorrência dos álcoois superiores 3-metil-1-butanol; 1-hexanol; e de 1-propanol como formadores do sabor e do aroma de kefir produzido com soro lácteo. Gran, Gadaga e Narvhus (2003) relataram a ocorrência de etanal e de ácido acético em Amsi, produto típico do Zimbábue, obtido pela fermentação espontânea do leite cru. Tais autores informaram que esses compostos são naturalmente formados durante a fermentação do soro do leite. Gallardo-Escamilla, Kelly e Delahunty (2007) mencionaram a ocorrência de acetaldeído, etanol, acetona, butadieno, acetoina e 2-furfural em produto elaborado a partir da fermentação do soro do leite bovino. Zhang et al. (2013) descreveram a acetoína como um dos principais componentes do leite e de lácteos.

Conforme Monnet e Corrieu (2007) algumas espécies de Streptococcus thermophilus sintetizam as enzimas acetohidóxi ácido sintetase e $\alpha$-acetolactato sintetase, as quais estão envolvidas na formação de 2,3-pentanodiona e 2,3-butanodiona a partir do piruvato (compostos naturalmente encontrados em leites fermentados).

Observou-se que a utilização de infusão de $C$. sinensis não descaracterizou o perfil de voláteis típico de lácteos e de bebida láctea fermentada. Dentre os demais compostos identificados nesta pesquisa, atenção deve ser dada ao linanol (álcool monoterpeno) pelos relatos de sua ocorrência e associação ao sabor e aroma do chá verde, produzido pela infusão de $C$. sinensis (MACHADO et al., 2007).

Kato e Shibamoto (2001), em pesquisa sobre a ocorrência de voláteis majoritários em chás preparados com C. sinensis, identificaram hexanal; 1-pentan-3-ol; heptanal; 1-pentanal; (Z)2-pentan-1-ol; (Z)-3-hexan-1-ol; linalol; e geraniol, destacando a correlação entre a quantidade de linalol e 2-hexenol sobre o sabor e aroma do chá verde. Nesta pesquisa, o linanol foi identificado em todas as formulações de bebida láctea, enquadrando-se entre o grupo de elementos majoritários. Em algumas formulações foi identificado 1-hexanol e o 3-pentanol.

Pelas informações da literatura, ainda escassas, pressupõe-se que o linalol tenha sido o principal composto responsável por conferir o sabor e aroma de $C$. sinensis ao produto, sendo observada, inclusive, tendência de aumento na percentagem de área desse composto conforme elevação da proporção de infusão adicionada.

Pesquisas têm demonstrado diversos benefícios do consumo regular de infusão de $C$. sinensis, os quais se traduzem em sua atividade antioxidante perante radicais livres, redução do percentual de gordura corporal, inibição de lipases pancreáticas, redução do colesterol total e de ácidos graxos livres no plasma sanguíneo e estimulação da termogênese (NELSON-DOOLEY et 
al., 2000; CHANTRE e LAIRON, 2002; WU et al., 2003; ASHIDA et al., 2004; KHAN e MUKHTAR, 2007). Por essa razão, ao se considerar a versatilidade das bebidas lácteas fermentadas para veicular componentes naturais da $C$. sinensis, com destaque para catequinas, oferece-se ao consumidor alternativa para a ingestão desses constituintes benéficos. Ao setor produtivo, oferecese oportunidade de agregação de valor, inovação e o atendimento dos crescentes segmentos de mercados demandadores de alimentos funcionais. Ao produto, veiculador de micro-organismos probióticos, agregam-se mais fatores de funcionalidade, o que pode estender o seu ciclo de vida.

\section{CONCLUSÃo}

O teor de massa seca, a umidade, o resíduo mineral fixo e a contagem total de bactérias láticas de formulações de bebida láctea fermentada não foram afetados pela quantidade de infusão de $C$. sinensis adicionada. Entretanto, os conteúdos de proteína, gordura e sódio foram menores quanto maior a percentagem de infusão incorporada ao produto. Verificou-se redução na viscosidade aparente das formulações mediante o aumento da quantidade de infusão adicionada.

A atividade antioxidante total das formulações foi maior conforme se elevou a quantidade de infusão adicionada.

A formulação de bebida láctea fermentada com adição de $30 \%$ de infusão de $C$. sinensis em soro lácteo destacou-se nos testes sensoriais, obtendo maior aceitação e maior intenção de consumo.

A utilização de infusão de $C$. sinensis para a obtenção do produto não descaracterizou o perfil de voláteis típico de lácteos e de bebida láctea fermentada. Pressupõe-se que o linalol tenha sido o principal composto responsável por conferir sabor e aroma de $C$. sinensis nesse produto, sendo observada, inclusive, tendência de elevação na percentagem de área desse composto conforme aumento da proporção de infusão adicionada.

\section{ABSTRACT \\ FERMENTED DAIRY BEVERAGE FORMULATED WITH Camellia sinensis}

The aim of this research was to characterize fermented milk drink formulated with Camellia sinensis. An infusion was prepared of chopped and dehydrated C. sinensis leaves in whey $(1 \% \mathrm{w} / \mathrm{v})$, which was added in the proportions of 10, 20, 30 and $40 \%$. The control consisted of sweetened fermented milk. Dry matter, moisture, ash, protein, fat, sodium, titratable acidity, lactic acid bacteria count, total antioxidant activity and viscosity were analyzed at the initial time of production and after 15 and 30 days of storage. The chromatographic determination of volatile compounds and also the acceptance and purchase intent testing were performed at the initial time of production. Dry matter content, moisture, ash and the total count of lactic acid bacteria were not affected by the amount of the infusion of $C$. sinensis that was added. The content of protein, fat and sodium reduced when the percentage of infusion was increased. A reduction in viscosity and increased total antioxidant activity occurred when there was an increase in the amount of infusion added. The formulation of fermented milk drink with $30 \%$ infusion of $C$. sinensis was most successful in terms of acceptability and intention to purchase. The use of infusion of $C$. sinensis did not decharacterize the profile of volatiles typical of fermented dairy beverages. It is assumed that linalool was mainly responsible for giving the flavor and aroma of $C$. sinensis to the product.

KEY-WORDS: Camellia sinensis; LACTIC ACID BACTERIA; VOLATILE COMPOUNDS; SENSORIAL ANALYSIS.

\section{REFERÊNCIAS}

1 Association of Official Analytical Chemistry (AOAC). Official methods of analysis of the AOAC International. $18^{\text {th }}$ ed. Gaithersburg, 2005.

2 American Public Health Association (APHA). Compendium of methods for the microbiological examination of 
foods. $4^{\text {ed }}$ ed. Washington, 2001.

3 ASHIDA, H.; FURUYASHIKI, T.; NAGAYASU, H.; BESSHO, H.; SAKAKIBARA, H.; HASHIMOTO, T. Anti-obesity actions of green tea: possible involvements in modulation of the glucose uptake system and suppression of the adipogenesisrelated transcription factors. Biofactors, v.22, p.135-140, 2004.

4 BRASIL. Ministério da Agricultura Pecuária e Abastecimento, Instrução Normativa nº 62, 29 de Dezembro de 2011. Regulamento técnico de identidade e qualidade de leite cru refrigerado. Diário Oficial [da] Republica Federativa do Brasil, Brasília, 30 de dezembro de 2011. Seção 1, p.6.

5 BRASIL. Ministério da Agricultura Pecuária e Abastecimento, Instrução Normativa n¹6, 23 de Agosto de 2005. Regulamento técnico de identidade e qualidade de bebida láctea. Diário Oficial [da] Rebublica Federativa do Brasil, Brasília, 8 de setembro de 2005, Seção 1, p.22-23.

6 BOGGS, J.M.; GAO, W.; ZHAO, J.; PARK, J.J.; LIU, Y.; BASU, A. Participation of galactosylceramide and sulfatide in glycosynapses between oligodendrocyte or myelin membranes. FEBS Letters, v.584, p.1771-1778, 2010.

7 CALDEIRA, L.A.; FERRÃO, S.P.B.; FERNANDES, S.A.A.; MAGNAVITA, A.P. A.; SANTOS, T.D.R. Desenvolvimento de bebida láctea sabor morango utilizando diferentes níveis de iogurte e soro lácteo obtidos com leite de búfala. Ciência Rural, v.40, n.10, p.2193-2198, 2010.

8 CASTELO-BRANCO, V.N.; TORRES, A.G. Capacidade antioxidante total de óleos vegetais comestíveis: determinantes químicos e sua relação com a qualidade dos óleos. Revista de Nutrição, v.24, p.173-187, 2011.

9 CECCHI, H.M. Fundamentos teóricos e práticos em análise de alimentos. 2. ed. Campinas: Ed. UNICAMP, 2003. p. 54-55.

10 CHAMMAS, G.I.; SALIBA, R.; CORRIEU, G.; BÉAL, C. Characterisation of lactic acid bacteria isolated from fermented milk "laban". International Journal of Food Microbiology, v.110, p.52-61, 2006.

11 CHAN, E.W.C.; LIM, Y. Y.; CHEW, Y.L. Antioxidant activity of Camellia sinensis leaves and tea from a lowland plantation in Malaysia. Food Chemistry, v. 102, p.1214-1222, 2007.

12 CHANTRE, P.; LAIRON, D. Recent findings of green tea extract AR25 (Exolise) and its activity for the treatment of obesity. Phytomedicine, v.9, p.3-8, 2002.

13 CODA, R.; LANERA, A.; TRANI, A.; GOBBETTI, M.; CAGNO, R. Yogurt-like beverages made of a mixture of cereals, soy and grape must: microbiology, texture, nutritional and sensory properties. International Journal of Food Microbiology, v.155, p.120-127, 2012.

14 CUNHA NETO, O.C.; OLIVEIRA, C.A.F.; HOTTA, R.M.; SOBRAL, P.J.A. Avaliação físico-química e sensorial do iogurte natural produzido com leite de búfala contendo diferentes níveis de gordura. Ciência e Tecnologia de Alimentos, v.25, n.3, p.448-453, 2005.

15 DAMIN, M.R.; ALCÂNTARA, M.R.; NUNES, A.P.; OLIVEIRA, M.N. Effects of milk supplementation with skim milk powder, whey protein concentrate and sodium caseinate on acidification kinetics, rheological properties and structure of nonfat stirred yogurt. Lebensmittel Wissenschaft und Technologie, v.42, p.1744-1750, 2009.

16 DE MARIA, C.A.B.; MOREIRA, R.F.A.; TRUGO, L.C. Componentes voláteis do café torrado Parte I. Compostos heterocíclicos: revisão. Química Nova, v. 22, p.209-217, 1999.

17 GALLARDO-ESCAMILLA, F.J.; KELLY, A.L.; DELAHUNTY, C.M. Mouthfeel and flavour of fermented whey with added hydrocolloids. International Dairy Journal, v.17, p.308-315, 2007.

18 GRAN, H.M.; GADAGA, H.T.; NARVHUS, J.A. Utilization of various starter cultures in the production of Amasi, a Zimbabwean naturally fermented raw milk product. International Journal of Food Microbiology, v.88, p.19-28, 2003.

19 GRYGORCZYK, A.; LESSCHAEVE, I.; CORREDIG, M.; DUIZER, L. Extraction of consumer texture preferences for yogurt: comparison of the preferred attribute elicitation method to conventional profiling. Food Quality and Preference, v.27, p. 215-222, 2013.

20 HEKMAT, S.; REID, G. Sensory properties of probiotic yogurt is comparable to standard yogurt. Nutrition Research, v.26, p.163-166, 2006.

21 INSTITUTO ADOLFO LUTZ. Métodos físico-químicos para análise de alimentos. 4. ed. 1.ed digital. São Paulo: IMESP, 2008. Disponível em: <http://www.ial.sp.gov.br>. Acesso em: 23/04/2011.

22 JANDAL, J.M. Studies on dried fermented dairy products prepared from sheep milk. Small Ruminant Research, v.21, p.217-220, 1996.

23 JUN, X.; DEJI, S.; YE, L.; RUI, Z. Comparison of in vitro antioxidant activities and bioactive components of green tea extracts by different extraction methods. International Journal of Pharmaceutics, v.408, p.97-101, 2011.

24 KAUSER, S. et al. Studies on the development and nutritional evaluation of apricot based yoghurt. Pakistan Journal of Biochemistry and Molecular Biology, v.44, p. 56-159. 2011. 
25 KATO, M.; SHIBAMOTO, T. Variation of major volatile constituentes in various green teas from Southeast Asia. Journal of Agricultural and Food Chemistry,v.49, p.1394-1396, 2001.

26 KHAN, N.; MUKHTAR, H. Tea polyphenols for health promotion. Life Science. v.81, p.519-533, 2007.

27 KODAMA, D.H.; GONÇALVES, A.E.S.S.; LAJOLO, F.M.; GENOVESE, M.I. Flavonoids, total phenolics and antioxidant capacity: comparison between commercial green tea preparations. Ciência e Tecnologia de Alimentos, v.30, p.10771082, 2010.

28 LAMB, A.; PAYNE, F.; XIONG, Y.L.; CASTILLO, M. Optical backscatter method for determining thermal denaturation of $\beta$-lactoglobulin and other whey proteins in milk. Journal of Dairy Science, v.96, p.1356-1365, 2013.

29 LARRAURI, J.A.; RUPÉREZ, P.; SAURA-CALIXTO, F. Effect of drying temperature on the stability of polyphenols and antioxidant activity of red grape pomace peels. Journal Agriculture and Food Chemistry, v.45, p.1390-1393, 1997.

30 LICÓN, C.C.; MENDOZA, J.H.; MAGGI, L.; BERRUGA, M.I.; ARANDA, R.M.M.; CARMONA, M. Optimization of headspace sorptive extraction for the analysis of volatiles in pressed ewes' milk cheese. International Dairy Journal, v.23, p.53-61, 2012

31 LIMA, J.M.; MAZZAFERA, P.; MORAES, W.S.; SILVA, R.B. Chá: aspectos relacionados à qualidade e perspectivas. Ciência Rural, v.39, p.1270-1278, 2009.

32 MACCIOLA, V.; CANDELA, G.; DE LEONARDIS, A. Rapid gas-chromatographic method for the determination of diacetyl in milk, fermented milk and butter. Food Control, v.19, p.873-878, 2008.

33 MACHADO, C.C.B.; BASTOS, D.H.M.; JANZANTTI, N.S.; FACANALI, R.; MARQUES, M.O.M.; FRANCO, M.R.B. Determinação do perfil de compostos voláteis e avaliação do sabor e aroma de bebidas produzidas a partir da ervamate (Ilex Paraguariensis). Química Nova, v.30, n.3, p.513-518, 2007.

34 MAGALHÃES, K.T.; DRAGONE, G.; PEREIRA, G.V.M.; OLIVEIRA, J.M.; DOMINGUES, L.; TEIXEIRA, J.A.; ALMEIDA e SILVA, J.B.; SCHWAN, R.F. Comparative study of the biochemical changes and volatile compound formations during the production of novel whey-based kefir beverages and traditional milk kefir. Food Chemistry, v.126, p.249-253, 2011.

35 MCKAY, D.L.; BLUMBERG, J.B. The role of tea in human heath: an update. Journal of the American College of Nutrition, v.21, p. 1-13, 2002.

36 MONNET, C.; CORRIEU, G. Selection and properties of alpha-acetolactate descarboxilase-deficient spontaneous mutants of Streptococcus thermophilus. Food Microbiology, v.24, p.601-606, 2007.

37 MOREIRA, R.F.A.; TRUGO, L.C.; DE MARIA, C.A.B. Componentes voláteis do café torrado. Parte II. Compostos alifáticos, alicíclicos e aromáticos. Química Nova, v.23, p.195-203, 2000.

38 NAYAK, A.; CARPENTER, G.H. A physiological model of tea-induced astringency. Physiology \& Behavior, v.95, p.290294, 2008.

39 NELSON-DOOLEY, C.; DELLA-FERA, M.A.; HAMRICK, M.; BAILE, C.A. Novel treatments for obesity and osteoporosis: targeting apoptotic pathways in adipocytes. Current Medical Chemistry, v.12, p.2215-2225, 2005.

40 NISHIYAMA, M.F.; COSTA, M.A.F.; COSTA, A.M.D.; SOUZA, C.G.M.; BÔER, C.G.; BRACHT, C.K.; PERALTA, R.M. Chá verde brasileiro (Camellia sinensis var assamica): efeitos do tempo de infusão, acondicionamento da erva e forma de preparo sobre a eficiência de extração dos bioativos e sobre a estabilidade da bebida. Ciência e Tecnologia de Alimentos, v.30, p.191-196, 2010.

41 PENNA, A.L.B.; THAMER, K.G. Efeito do teor de soro, açúcar e de frutooligossacarídeos sobre a população de bactérias lácticas probióticas em bebidas fermentadas. Revista Brasileira de Ciências Farmacêuticas, v.41, p.393-400, 2005.

42 PHEROBASE. Pherobase database of insect pheromones and semiochemicals. Disponível em: [http//: pherobase. com]. Acesso em: 12/09/2012.

43 POLOVKA, M.; BREZOVÁ, V.; STAŠKO, A. Antioxidant properties of tea investigated by EPR spectroscopy. Biophysical Chemistry, v.106, p.39-56, 2003.

44 ROCHA, C.; COBUCCI, R.M.A.; MAITAN, V.R.; SILVA, O.C. Elaboração e avaliação de iogurte sabor frutos do cerrado. Boletim do CEPPA, v. 26, n. 2, p. 255-266, 2008.

45 ROSSETTI, D.; BONGAERTS, J.H.H.; WANTLING, E.; STOKES, J.R.; WILLIAMSON, A.M. Astringency of tea catechins: more than an oral lubrication tactile percept. Food Hydrocolloids, v.23, p.1984-1992, 2009.

46 RUFINO, M.S.M.; ALVES, R.E.; BRITO, E.S.; MORAIS, S.M.; SAMPAIO, C.G.; PÉREZ-JIMENEZ, J.; SAURA-CALIXTO, F.D. Metodologia científica: determinação da atividade antioxidante total em frutas pela captura do radical livre DPPH. Fortaleza, Ceará: Empresa Brasileira de Pesquisa Agropecuária (EMBRAPA), 2007. (Comunicado técnico online, 127).

47 SABOYA, L.V.; OLIVEIRA, A.J.; FURTADO, M.M.; SPADOTI, L.M. Efeitos físico-químicos da adição de leite reconstituído na fabricação de queijo minas frescal. Ciência e Tecnologia de Alimentos, v.18, n.4, p.368-378, 1998. 
48 SANDOVAL-CASTILLA, O.; LOBATO-CALLEROSA, C.; AGUIRRE-MANDUJANOA, E.; VERNON-CARTERB, E.J. Microstructure and texture of yoghurt as influenced by fat replacers. International Dairy Journal, v.14, p.151-159, 2004.

49 Statistical Analysis System Institute (SAS). User's guide: statistics. Version 9.0. Raleigh: North Carolina State University, 2002.

50 SECKIN, A.K.; OZKILINE, A.Y. Effect of some prebiotics usage on quality properties of concentrated yoghurt. Journal of Animal and Veterinary Advances, v.10, p.1117-1123, 2011.

51 SERVILI, M.; RIZZELLO, C.G.; TATICCHI, A.; ESPOSTO, S.; URBANI, S.; MAZZACANE, F.; DI MAIO, I.; SELVAGGINI, R.; GOBBETTI, M.; DI CAGNO, R. Functional milk beverage fortified with phenolic compounds extracted from olive vegetation water, and fermented with functional lactic acid bacteria. International Journal of Food Microbiology, v.147, p.45-52, 2011.

52 SIEBERT, K.J.; MAEKAWA, A.E.; LYNN, P. The effects of green tea drinking on salivary polyphenol concentration and perception of acid astringency. Food Quality and Preference, v.22, p.157-164, 2011.

53 SOLA-LARRANAGA, C.; NAVARRO-BLASCO, I. Chemometric analysis of minerals and trace elements in raw cow milk from the community of Navarra, Spain. Food Chemistry, v.112, n.1, p.189-196, 2009.

54 STELWAGEN, K. Mammary gland, milk biosynthesis and secretion. In: ENCYCLOPEDIA of dairy sciences. $2^{\text {th }}$ ed. New York: Academic Press, 2011. p.367-372.

55 TEIXEIRA, L.V.; FONSECA, L.M. Perfil físico-químico do soro de queijos mozarela e minas-padrão produzidos em várias regiões do estado de Minas Gerais. Arquivo Brasileiro de Medicina Veterinária e Zootecnia, v.60, n.1, p.243$250,2008$.

56 THAMER, K.G.; PENNA, A.L.B. Caracterização de bebidas lácteas funcionais fermentadas por probióticos e acrescidas de prebióticos. Ciência e Tecnologia de Alimentos, v. 26, p. 589-595, 2006.

57 VAHEDI, N.; TEHRANI, M.M.; SHAHIDI, F. Optimizing of fruit yoghurt formulation and evaluating its quality during storage. American-Eurasian Journal of Agricultural and Environmental Science, v.3, p.922-927, 2008.

58 ZHANG, Y.; LI, S.; LIU, L.; WU, J. Acetoin production enhanced by manipulating carbon flux in a newly isolated Bacillus amyloliquefaciens. Bioresource Technology, v.130, p.256-260, 2013.

59 World Health Organization (WHO). Guideline: Sodium intake for adults and children. Genebra: WHO, 2012,56 p. Disponível em: <http://www.who.int/nutrition/publications/guidelines/sodium_intake_printversion.pdf>. Acesso em; $15 / 01 / 2013$

60 WU, C.H.; LU, F.H.; CHANG, C.S.; CHANG, T.C.; WANG, R.H.; CHANG, C.J. Relationship among habitual tea consumption, percent body fat, and body fat distribution. Obesity Research, v.11, p.1088-1095, 2003.

\section{AGRADECIMENTOS}

Os autores agradecem ao CNPq, CAPES, FINEP e FAPEMIG. 